\title{
Tool life equation for blanking 18-8 stainless steel strips ${ }^{(\bullet)}$
}

\author{
F. Faura ${ }^{(*)}$, J. López ${ }^{(*)}$, J. Sanes ${ }^{(*)}$ y A. García ${ }^{(*)}$
}

\begin{abstract}
Hereinafter it is presented a model for the behaviour and life of circular blanking tool used in sheet forming processes of 18-8 stainless steel (sheet thickness: $1 \mathrm{~mm}$ ). Firstly it has analyzed the different studies that have previously delt with this problem. Secondly taking into account recently made experiments, it is proposed a simple formulation to predict tool life with enough reliability. To this purpose it has examined different parameters in the wear process, inferring from these the fundamental parameters that regulate them and about which the different equations have been configurated. Blanking tests were performed using a $20 \mathrm{t}$ press at a speed of 150 strokes $/ \mathrm{min}$. Punch materials used in these tests were AISI A2 and AISI D2 with diameters between 1.5 and $10 \mathrm{~mm}$. The blanking tests were performed at a clearance between 5 and $20 \%$ of the work material thickness.
\end{abstract}

Keywords: Tool wear. Tool life. Blanking. Stainless steel.

\section{Ecuación de vida de herramienta en el punzonado de chapa de acero inoxidable 18-8}

\begin{abstract}
Resumen En el presente artículo se presenta un modelo de ecuación de vida de herramientas para punzonado circular de chapa de acero inoxidable 18-8 (1 mm de espesor). Se han analizado inicialmente los diferentes estudios que previamente han abordado este problema. Posteriormente, teniendo en cuenta los experimentos realizados recientemente, se propone una formulación simple para predecir con fiabilidad suficiente la vida de la herramienta. Para este propósito se han examinado los diferentes parámetros que afectan al proceso de desgaste, inferiendo a partir de estos, los parámetros fundamentales que lo regulan y sobre los cuales se han configurado las diferentes ecuaciones. Los ensayos fueron realizados en una prensa de $20 \mathrm{t}$ y una velocidad de punzonado de 150 golpes $/ \mathrm{min}$. Los materiales de los punzones usados en los ensayos fueron AISI A2 y AISI D2 con diámetros comprendidos entre 1,5 y $10 \mathrm{~mm}$. Los ensayos se realizaron para juegos de corte comprendidos entre un 5 y $20 \%$ del espesor de la chapa.
\end{abstract}

Palabras clave: Desgaste de herramienta. Vida de herramienta. Punzonado. Acero inoxidable.

\section{INTRODUCTION}

Press working is an extremely important process for the production of precision machine parts. Blanking and piercing account for about $70 \%$ of all the press work. Wear of blanking tools has become a very important problem from the economic standpoint, because of its great influence on the accuracy of the blanked parts and on the tool cost.

Although blanking wear is a very important part in the metal forming process, there are only a few

(•) Trabajo recibido el día 24 de noviembre de 1997 y aceptado en su forma final el 12 de febrero de 1998.

(*) Dpto. Ingeniería de Materiales y Fabricación. E.T.S. Ingenieros Industriales. Universidad de Murcia. Paseo Alfonso XIII, 34. 30203-Cartagena. Murcia (España). experimental reports on this subject and theoretical studies of this phenomenon have been scarce.

Blanking tools used in forming processes work under aggressive mechanical, thermal and chemical conditions which determine tool wear. These wear mechanisms heavily affect tool life and the final part precision.

Under these circumstances, the necessity for tool life prediction models becomes clear. Such models, should allow the introduction of tool life considerations in the production planning programs, thus avoiding undesirable machine production interruptions.

In the present article, the main aim is to determine some models of tool life equations, which allow to predict its duration before getting to 
a certain wear value, that may be an objetive function (minimum cost, maximum production, maximum quality, and so on).

Simple expresions are searched in order to obtain the relationship between tool duration (number of strokes carried out, $n$ ) and the fundamental technical parameter of the process. In this manufacturing process there are some relevant factors, such as working material, diameter, tool stiffness, lubrication, etc., however, the most important factor is clearance $(C l)$, because it affects not only the finishing quality but also tool wear, having the most influence over its final duration.

Therefore the objective is to develop a model able to produce simple relations $\mathrm{n}$ - $\mathrm{Cl}$ according to different working conditions.

\section{BACKGROUND}

In 1963 the first work by Buchmann (1) about wear and its influence on the blanking of steel sheet was published. This work can be considered the starting point of the current studies on these phenomena, in which the measure of punch and die face flank, and edge wear were considered for the first time, evaluating them using very similars techniques to those used at present (2).

This last guideline was used in different works (3). More recently they are also relevant to the works of Zivanovic (4).

In Japan, these studies started later than in Germany, being proffesor Maeda who did the first contribution. At first, Matsuno et al. (5) investigated comprehensively the tool wear such as crater wear, crater-slope wear and slope wear at each part of a tool in the blanking of silicon steel sheets.The effects of clearance, restriction of work material, finish of cutting edge, etc., on tool wear were examined and general knowledge for tool wear was summarized.

Since 1971, research on the wear of tools for difficult materials to work started (6). Tool, stainless and bainite steels were dealt with as work materials. In this work observations of worn surfaces by electron microscope and measurement of tool material compositions and adhesion state by EPMA were useful.

Effects of tool materials and blank holder on tool wear were summarized as follows. At tool flanks, scratch wear is dominant and the amount of wear is governed by the magnitude of the effective hardness of the tool. On the other hand, at the sides of the tools adhesive wear is dominant and at the top of the cutting edge both types of wear are combined. Flank and side wear are reduced considerably by the adoption of a blank holder or by the increase in working speed but top wear is not. Sintered high speed tool steel is not apt to develop defects during heat treatment and is strong to scratch wear.

One of the major theoretical advances in the modeling of the wear processes was due to Takaishi et al. in 1984 (7), from experimental results obtained by Maeda's group. These models were based on data statistics.

\section{GENERAL PLANNING}

The general equation model selected is simple, easy and quick to use, though it is necessary to refer to its application field. With this purpose the fundamental process parameter has been chosen, $\mathrm{Cl}$, being the rest of parameters initially fixed.

The present study refers to the following working conditions:

- Sheet material, 18-8 stainless steel.

- Sheet thickness, $1 \mathrm{~mm}$.

- Circular blanking.

The work material is a decisive factor, since it affects directly the influence that the rest of factors have on the wear. In this way, there are expresions for some base materials that relate the wear $W$ $\left(\mu \mathrm{m}^{2}\right)$ to the most important parameters in the different cases. For the studied material, Takaishi et al. published one of these expresions [1], where the appeared variables were the number of strokes $n$, total elongation $e$ of selected material, punch diameter $d$, tool effective hardness $H_{v e}$, and clearance, $\mathrm{Cl}$. Other materials would probably produce different quantitative and even qualitative equations to these proposals.

Since for stainless steel the wear relationship with the other parameters was developed by Takaishi, these equations [1] is a basic starting reference for the proposed modelling.

This study has been directed like Takaishis's in stainless steel sheet (AISI 304, thickness $1 \mathrm{~mm}$ ). Two variants from this steel will be used clasifying them as I and II according to the different values of $e$.

For this kind of material and its thickness the expression developed by Takaishi is the following:

$$
\begin{gathered}
W=\frac{n^{2}}{H_{\mathrm{ve}}}\left(\begin{array}{l}
-0,3 \cdot 10^{-2} \mathrm{Cl}+0,11 \cdot 10^{-2} e+0,15 \cdot 10^{-3} \mathrm{Cl}^{2}- \\
-0,18 \cdot 10^{-7} e . n+0,90 \cdot 10^{-10} \text { Cl.e.d.n- }
\end{array}\right. \\
\left.\quad \begin{array}{l}
-0,39 \cdot 10^{-4} \text { e.d }+0,34 \cdot 10^{-5} \mathrm{Cl} \text {.e. } \mathrm{d}^{2}- \\
-0,24 \cdot 10^{-9} \mathrm{Cl}^{2} \cdot d . n+0,48 \cdot 10^{-7} \mathrm{Cl} . n
\end{array}\right)
\end{gathered}
$$

The previous study has been applied to four samples referred to as I, II, III and IV, and the initially fixed conditions are those shown in table I. 
TABLE I.- References

TABLA I.-Referencias

\begin{tabular}{|l|c|c|c|}
\hline & Work material & Punch material & Punch diameter, \\
& Elongation, $\%$ & Efective hard & mm \\
\hline Type I & AISI 304, e $=45$ & AISI D2, Hve $=1,017$ & 10 \\
Type II & AISI 304, e $=45$ & AISI D2, Hve $=1,017$ & 1.5 \\
Type III & AISI 304, e $=30$ & AISI A2, Hve $=860$ & 10 \\
Type IV & AISI 304, e $=30$ & AISI A2, Hve $=860$ & 1.5 \\
\hline
\end{tabular}

In order to solve the deficiency of experimental results and to be able to validate the models of the studied cases different tests have been carried out in a $20 \mathrm{t}$ press at a punching speed of 150 strokes/min, and an automatized feeding-evacuation system that ensures an advance speed aproximately $30 \mathrm{~mm} / \mathrm{s}$ (Fig. 1). The quantification of wear was done by means of a profile projector with a great resolution (maximum dispersion $0.05 \%$ ) which permitted to obtain the mean of the worn surface, through the measuring according to two perpendicular planes on a punch axis (Fig. 2).

The tests carried out with these equipments were perfomed for diameters: $6,8,10,12,14$ and for clearances: $5,8,11,14$ and $17 \%$. The measures were perfomed in intervals of nearly 5,000 strokes depending on each particular case.

\section{GENERAL DEVELOPMENT OF MODELS}

The study was perfomed at a clearance $(\mathrm{Cl})$ between 5 and $20 \%$ of the thickness of work material. These values were selected with the following criteria:

- The lowest value (5\%) has been used in previous studies (6) and it has been demostrated that for lower clearance values, undesirable effects appear such as cracks, chipping, cold welding, etc., that are able to interrupt the forming process even before 3,000 strokes.

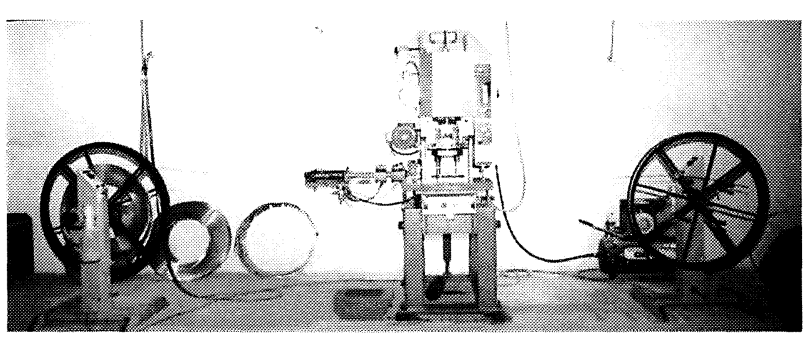

FIG. 1.- Equipment for blanking test.

FIG. 1.-Equipo de ensayos de punzonado.

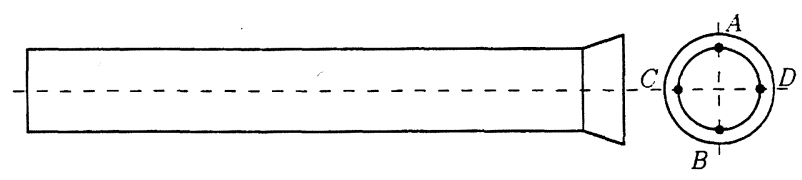

FIG. 2.- Points of measuring in tool.

\section{FIG. 2.-Puntos de medida en herramienta.}

- The highest value $(20 \%)$ has been fixed following quality considerations. Clearances higher than this can lead to important defects (burrs height, plastic deformation, etc.) (8).

If a mathematical ad hoc treatment of equation [1] (singled for the conditions of our approaches) is performed, in order to observe the general behavior of tool life, $n$, versus clearance $\mathrm{Cl}$, it is possible to appreciate a general behavior of wear in the studied references.

In figure 3 , it is possible to observe three clearly differentiated zones with growing clearances.

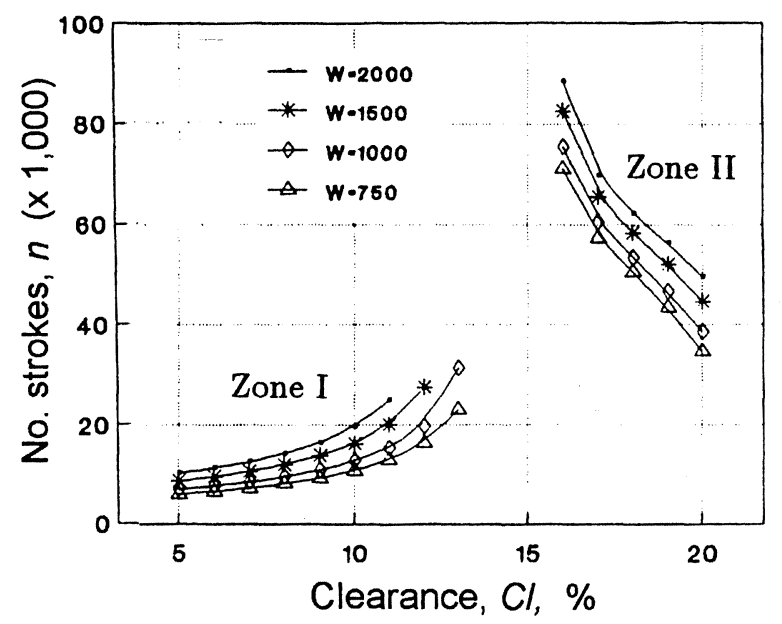

FIG. 3.- Number of strokes versus clearances for different wear.

FIG. 3.- Número de golpes frente a juegos de corte para distintos valores de desgaste. 
- A first zone, called zone I, ranging from $5 \% \mathrm{Cl}$ to a variable superior limit, where the number of possible strokes before a given wear value increases clearance. Its clearance values vary between those of highest geometry precision and those of minimum tool wear.

- A second zone appears where numeric real values of the equation [1] have not been obtained. This could be called zone of optimum clearance, whenever it is reasonable from the point of view of tool wear, because the theoretical interpretation of the results would lead to admit that number of possible strokes is limited for the fixed conditions of wear.

- Finally, a third zone is observed, starting at the superior limit of the preceding zone and reaching the top limit in each studied case. In this zone the number of possible strokes decreased with increasing clearance. Therefore tool life diminishes, and quality or accuracy of workpieces determine shape defects (plastic deformation or edge drawn in, depth of crack penetration and burrs height).

As above stated, the working limits must be kept, when it is possible, within the zone of optimum clearance. In some cases, quality specifications force to work inside zone I and in these cases it is important to have tool life prediction models that provide life criteria to be used in production planning programs, therefore it will be possible to avoid non-programmed interruptions of the machines.

With the experimental results obtained (Table II) which have been partially shown in figure 4 , and

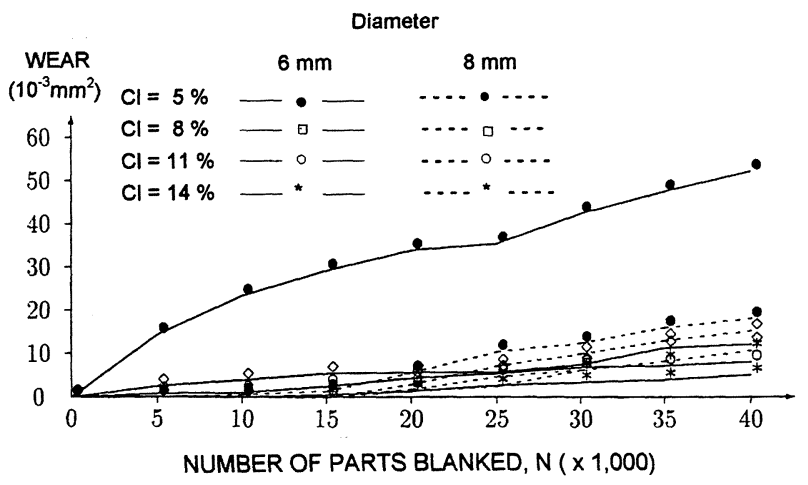

FIG. 4.- Number of strokes versus wear.

FIG. 4.- Número de golpes frente a desgaste.

with the theoretical procedure of the equation [1], several tool life models were tested: $n=\mathrm{a} C l^{\mathrm{b}}$; $n=A+P_{1} C l^{\mathrm{P} 2}$ and $n=F_{1}+F_{2} C l^{\alpha}$.

Although all these are satisfactory with the established target, the first and the second one can present some trouble when wear is introduced as an independent variable in the model to offer a more general model. In the first model, considerable deviations are caused with small values of $W$ and $\mathrm{Cl}$, while in the second model it is not possible to map the parameters $P_{1}$ and $P_{2}$ with $W$.

The third model proposed here represents a good equilibrium between simplicity and precision:

$$
n=F_{1}+F_{2} C l^{\alpha}
$$

Some results are shown on table III with the corresponding correlation coefficients.

TABLE II.- Wear from results of tests

TABLA II.- Valores del desgaste obtenidos de los ensayos

\begin{tabular}{|c|c|c|c|c|c|c|c|c|c|c|c|}
\hline \multirow{3}{*}{$\begin{array}{c}\text { No. } \\
\text { strokes } \\
\times 1,000\end{array}$} & \multicolumn{11}{|c|}{ Clearance, $\mathrm{Cl}$} \\
\hline & \multicolumn{2}{|c|}{$\begin{array}{c}0.05 \\
\text { diameter }\end{array}$} & \multicolumn{2}{|c|}{$\begin{array}{c}0.08 \\
\text { diameter }\end{array}$} & \multicolumn{2}{|c|}{$\begin{array}{c}0.11 \\
\text { diameter }\end{array}$} & \multicolumn{3}{|c|}{$\begin{array}{c}0.14 \\
\text { diameter }\end{array}$} & \multicolumn{2}{|c|}{$\begin{array}{c}0.17 \\
\text { diameter }\end{array}$} \\
\hline & 6 & 8 & 6 & 8 & 6 & 8 & 6 & 8 & 10 & 14 & 10 \\
\hline 5 & 14.442 & - & 2.499 & - & 0.8075 & - & - & - & - & - & - \\
\hline 10 & 23.490 & 0.5750 & 4.020 & - & 1.0770 & - & - & - & - & - & - \\
\hline 15 & 29.463 & 1.4375 & 5.603 & - & 2.5477 & - & 0.5747 & - & - & - & - \\
\hline 20 & 34.093 & 5.7200 & 5.817 & 3.0175 & 4.4602 & 1.8875 & 1.4865 & 1.5275 & - & 1.1200 & - \\
\hline 25 & 35.716 & 10.618 & 5.817 & 7.2500 & 5.6030 & 4.8175 & 2.8350 & 2.5450 & - & 3.7250 & 0.8825 \\
\hline 30 & 42.638 & 12.620 & 7.632 & 10.138 & 6.9795 & 6.3900 & 3.5073 & 6.3675 & 3.5750 & 5.8100 & 1.7133 \\
\hline 35 & 47.690 & 16.152 & 11.466 & 13.183 & 7.3613 & & 4.1665 & 8.3825 & 5.2360 & 8.0325 & 1.7903 \\
\hline 40 & 52.456 & 18.268 & 12.314 & 15.420 & 8.2467 & & 5.1975 & 10.853 & 5.796 & 9.1975 & 2.1543 \\
\hline
\end{tabular}


TABLE III.- Regression results (Ref. Type I)

TABLA III.- Resultados de la regresión

\begin{tabular}{|l|ll|c|}
\hline \multirow{2}{*}{ Wear, $\mu \mathrm{m}^{2}$} & \multicolumn{2}{|c|}{ Equat. Coef. } & Correlat. Coef. \\
\cline { 2 - 3 } & $F_{1}$ & $F_{2}$ & $R$ \\
\hline 2000 & 10524 & 0.146 & 0.998 \\
1500 & 8713 & 0.126 & 0.997 \\
1000 & 6710 & 0.101 & 0.986 \\
750 & 5631 & 0.08 & 0.994 \\
500 & 4374 & 0.062 & 0.986 \\
400 & 3989 & 0.057 & 0.981 \\
300 & 3437 & 0.049 & 0.989 \\
200 & 2825 & 0.038 & 0.992 \\
\hline
\end{tabular}

Besides it is possible to observe a graph with the performed regressions $(n-C l)$ and the parameter $F_{1}$ versus $W$ for one reference (Fig. 5).

In order to introduce wear as a variable in this model, the relationship between the wear parameter and the constant $F_{1}$ and $F_{2}$ was studied using lineal equations of the type: $\left(F_{1}=\mathrm{a}+\mathrm{bW}\right)$ and $\left(F_{2}=\mathrm{c}+\right.$ $\mathrm{d} W)$.

In every case, correlation coefficients are higher than 0.97 .

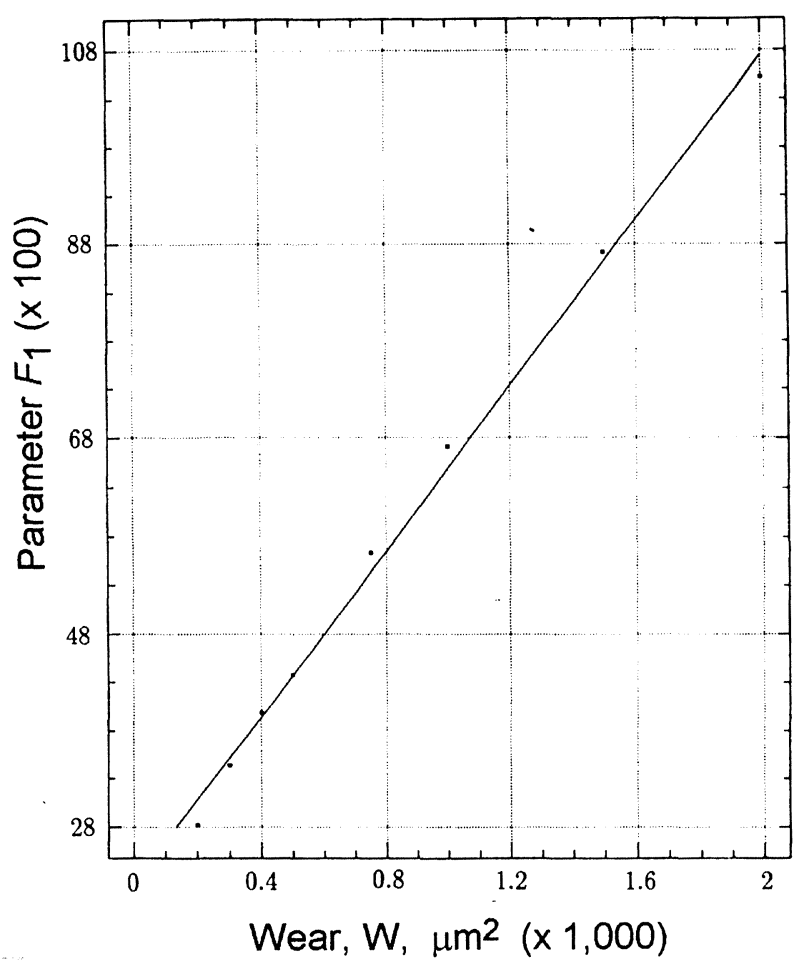

The general proposed model results then:

$$
n=(\mathrm{a}+\mathrm{b} W)+(\mathrm{c}+\mathrm{d} W) C l^{\alpha}
$$

Coefficients obtained for each of the references studied are shown on table IV.

Our model for the zone II consists of lineal equations that were selected for simplicity reasons: $n=F_{1}+F_{2} C l$. It can be noted that this model is a simplification of that proposed for zone I, making $\alpha=1$.

In order to introduce wear as a variable in this model, the constants $F_{1}$ and $F_{2}$ were studied using lineal equations as in the previous case: $\left(F_{1}=\mathrm{a}+\right.$ $\mathrm{b} W)$ and $\left(F_{2}=\mathrm{c}+\mathrm{d} W\right)$.

A particular result is obtained for references of type II (Table IV). In this case, lineal regressions are excellent if wear values are divided into two different fields: $W>800 \mu \mathrm{m}^{2}$ and $W<800 \mu \mathrm{m}^{2}$, finally so this solution was adopted.

From all the above stated, it follows that the final model for zone II is of the type:

$$
n=(\mathrm{a}+\mathrm{b} W)+(\mathrm{c}+\mathrm{d} W) C l
$$

Coefficients a, b, c and d are shown on table IV for each reference.

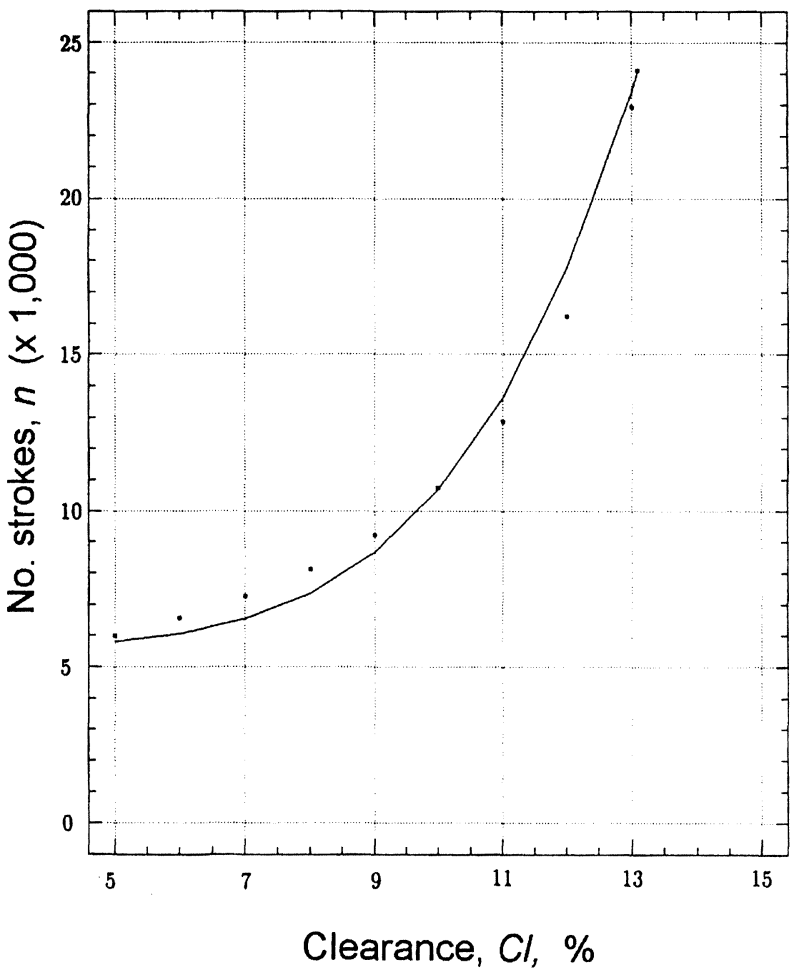

FIG. 5.- Performed regression (Ref. Type I).

FIG. 5.-Regresión realizada (Ref. Tipo I). 
TABLE IV.- Tool life equation coefficients

TABLA IV.- Coeficientes de la ecuación de vida de las herramientas

\begin{tabular}{|c|c|c|c|c|c|c|c|c|c|}
\hline \multirow{3}{*}{ Coef. } & \multicolumn{4}{|c|}{ Zone I } & \multicolumn{5}{|c|}{ Zone II } \\
\hline & \multirow[t]{2}{*}{ Type I } & \multirow[t]{2}{*}{ Type II } & \multirow[t]{2}{*}{ Type III } & \multirow[t]{2}{*}{ Type IV } & \multirow[t]{2}{*}{ Type I } & \multicolumn{2}{|c|}{ Type II } & \multirow[t]{2}{*}{ Type III } & \multirow[t]{2}{*}{ Type IV } \\
\hline & & & & & & $W>800$ & $W<800$ & & \\
\hline $\mathrm{a}$ & 2237 & 3559 & 2769 & 3332 & 193263 & 7401.8 & 38615 & 128157 & 37226 \\
\hline b & 4.26 & 2.98 & 6.24 & 5.5 & 18.41 & 55.0 & 16.22 & -9.59 & 20.68 \\
\hline $\mathrm{c}$ & 0.0322 & -0.016 & 0.01 & 0.017 & -8552.6 & -7.74 & -1524.5 & -5043.7 & -1572.17 \\
\hline $\mathrm{d}$ & $610^{-5}$ & $10^{-3}$ & $410^{-5}$ & $9.410^{-5}$ & -0.255 & -2.46 & $-0,57$ & 1.044 & 0.862 \\
\hline$\alpha$ & 4.8 & 3.8 & 5.8 & 5.4 & 1 & 1 & 1 & 1 & 1 \\
\hline
\end{tabular}

\section{RESULTS AND DISCUSSIONS}

Regarding the results obtained for the evolution of tool life with clearance and acceptable wear, the next evaluation can be proposed:

- In zone I, ranging from $5 \% \mathrm{Cl}$ to a variable superior limit, where this limit depends both on the reference taken and on the degree of acceptable wear. Thus, in all these examples, the superior limit decreases with increasing admitted wear. This zone is specially important. Its clearance values vary between those of highest geometric precision and those of minimum tool wear. This is the most commonly used working zone when looking for a compromise between quality and economic considerations.

- A second zone that, from the point of view of tool wear, could be called zone of optimum clearance, where tool life is long enough to be considered a cause of interruption of the manufacturing process. The limits of this second zone entirely depend on the initial working conditions (work material, diameter, etc.) and on the maximum acceptable wear. In this way, for example, in reference to type I, the superior limit is $15 \%$ with all admitted wear, even, sometimes it is a single value. When wear increases the inferior limit decreases, then a clearance band of minimum wear can be seen. Thus, for $W=2,000 \mu \mathrm{m}^{2}$, the limits of this band are 12 and $15 \%$ respectively.

- In the third zone, the number of blanks decreases with incresing clearances. It could be caused by the influence that the increase of deformations of work material exercises on wear, upon increasing clearance.

This zone is not usually employed as working zone. The reasons are essentially two: a) The minimum wear clearance has been supposed and tool costs have risen.

b) The quality or accuracy of workpieces is much lower on the blanke surface since larger clearance determine shape defects (plastic deformation or edge drawn in, depth of crack penetration and burrs height).

To check these models, several application examples are shown, fixing random values of wear and clearance and obtaining the corresponding number of strokes. In this way, Takaishi's equation values [1] $\left(n_{\mathrm{T}}\right)$ are compared to the models, calculating the deviations, for each reference. The results are shown in table $\mathrm{V}$.

In order to validate the models within the limitations with published experimental data (6) and tests in laboratory, it is necessary to use the model in another way, because the references and the tests provide values of wear for a fixed number of strokes. So, a value for $n$ must be fixed and the obtained implicit equations in each reference must be solved.

Thus, in reference type I, with clearance $10 \%$ and number strokes 20,000 , the obtained wear is $2,150 \mathrm{\mu m}^{2}$. The model provides wear of 1,955 $\mu \mathrm{m}^{2}$, therefore the relative error is $9 \%$. With the same clearance and $n=15000$ strokes, the experimental datum is $W=1,220 \mu \mathrm{m}^{2}$. The model provides a value of $W=1,335 \mu \mathrm{m}^{2}$ and the error is $9 \%$.

Also, it is possible to make comparisons for the reference type IV. In this case, with 20,000 strokes and clearance $10 \%$ the experimental wear is 380 $\mu \mathrm{m}^{2}$, providing the application of model $W=425$ $\mu \mathrm{m}^{2}$, therefore the error is $12 \%$. With $n=15,000$ strokes, the model provides $254 \mu \mathrm{m}^{2}$ that it is like the experimental value.

With these results, it can be said that the model III satisfies the previous targets. 
TABLE V.- Results of the application examples

TABLA V.-Resultados de los ejemplos aplicados

\begin{tabular}{|c|c|c|c|c|c|}
\hline References & $W, \mu \mathrm{m}^{2}$ & $C l$ & $n$ & $n_{\mathrm{T}}$ & $\epsilon_{\text {relativo }}$ \\
\hline \multirow{5}{*}{ I } & 2000 & 10 & 20360 & 19536 & 4.2 \\
& 1000 & 10 & 12315 & 12661 & 2.7 \\
& 500 & 10 & 8292 & 8554 & 3.0 \\
& 200 & 10 & 5878 & 5228 & 12 \\
& 750 & 8 & 7101 & 8115 & 12.5 \\
& 1500 & 7 & 10016 & 10661 & 6.0 \\
\hline \multirow{5}{*}{ II } & 1000 & 5 & 6985 & 6972 & 0.18 \\
& 2000 & 5 & 10417 & 10298 & 0.15 \\
& 2000 & 9 & 17907 & 17962 & 0.3 \\
& 1000 & 11 & 15457 & 15537 & 0.5 \\
& 800 & 12 & 15834 & 16254 & 2.6 \\
III & 700 & 13 & 17341 & 18381 & 5.6 \\
\hline \multirow{6}{*}{ IV } & 1000 & 8 & 17656 & 17313 & 1.9 \\
& 1000 & 6 & 10639 & 10802 & 1.5 \\
& 1000 & 7 & 12995 & 13152 & 1.19 \\
& 750 & 6 & 8753 & 9196 & 4.8 \\
& 750 & 7 & 10638 & 11129 & 4.4 \\
& 750 & 8 & 14367 & 14439 & 0.4 \\
\hline & 1000 & 8 & 17188 & 17097 & 0.5 \\
& 800 & 8 & 14673 & 14508 & 1.1 \\
& 700 & 8 & 13415 & 13254 & 1.21 \\
& 600 & 8 & 12143 & 11997 & 1.2 \\
& 1000 & 6 & 10599 & 10798 & 1.8 \\
& 600 & 9 & 17069 & 16397 & 4.0 \\
\hline \multirow{6}{*}{}
\end{tabular}

\section{CONCLUSIONS}

The first studies show three different zones. One zone, where the number of strokes increases with increasing clearances. Clearances in this zone vary between maximum precision clearance and minimum wear clearance. This zone is the most appropriate working one when both factors must be considered.
There also exists an optimum clearance zone which must be used when minimum tool wear is the main priority.

Finally, there is a third zone with clearances higher than the optimum ones, where the number of blanks decreases with increasing clearances. This third zone is not usually employed as a working zone due to the increasing tool costs, while the quality obtained is considerably lower.

It was proposed a life equation model that satisfactorily predicts the number of strokes for all working conditions as a function of the clearance and of the maximum acceptable tool wear.

\section{Acknowledgements}

The authors thank the Comisión Interministerial de Ciencia y Tecnología (CICYT) for the financial support to implement the investigation project TAP94-0886-C03-01, by which this work was made possible.

\section{REFERENCES}

(1) BuchmanN, K. Werkstattstech. Maschinenbau., (53), 1963: 128-134.

(2) Faura, F., Lopez, J. and Sanes, J. Rev. Metal. Madrid., 33 (5), 1997: 304-310.

(3) Sondershaus, E. Mitt. DFBO., (10), 1968: 142-156.

(4) Zivanovic et al., Bänder Bleche Rohre., (10) 1981: 267270.

(5) Matsuno, K. and Maeda, T. Bull. Japan Soc. Mech. Engng., (10), 1967: 197.

(6) Maeda, T. and Aoki, I. J. Fac. Eng. Univ. Tokyo (B)., Vol. XXXII, 1974: 443-475.

(7) Takaishi, K., Kondo, T., Sugiyama, S. and Mizutame, M. Adv. Technol. Plast., Vol. 2, 1984: 833-838.

(8) Faura, F., Sebastian, M.A., Dominguez, M. y Garcia, A. Def. Metálica., (214), 1994: 13-21. 